\title{
Whole-House Measurements of Standby Power Consumption
}

\author{
J.P. Ross \\ University of California, Berkeley, USA \\ Alan Meier* \\ Lawrence Berkeley National Laboratory, USA
}

\begin{abstract}
We investigated the variation in standby power consumption in ten California homes. Total standby power in the homes ranged from 14-169 W, with an average of $67 \mathrm{~W}$. This corresponded to 5\%-26\% of the homes' annual electricity use. The appliances with the largest standby losses were televisions, set-top boxes and printers. The large variation in the standby power of appliances providing the same service demonstrates that manufacturers are able to reduce standby losses without degrading performance. Replacing existing units with appliances with $1 \mathrm{~W}$ or less of standby power would reduce standby losses by $68 \%$.
\end{abstract}

\section{INTRODUCTION}

Standby power use now occurs in many modern appliances. These appliances can not be turned "off" without being unplugged or continue to draw power while not performing their primary purpose. Standby power has become a growing concern in the international community. Studies in Germany (Rath et al. 1997), Japan (Nakagami et al. 1997), the Netherlands (Siderius 1998), and the United States (Meier et al. 1999, Huber et al. 1997) have found that standby power accounts for as much as $10 \%$ of national residential electricity use. These studies (and others) have resulted in standby measurements of thousands of appliances, but few measurements of total standby power consumption in individual homes. To our knowledge the Jyukankyo Research Institute in Japan (Murakoshi 2000) and ADEME in France (Sidler 2000) have conducted the only studies of whole-house standby power consumption, but the results have not been widely circulated. Whole-house measurements of standby provide important perspectives on the variation of standby electricity consumption in individual homes and the likely impact of policies aimed at reduction.

We report here the results of standby measurements in ten Northern California homes. The objectives of the study were to measure standby power in a large number of homes, estimate potential savings from reductions in standby power use, and test the accuracy of alternative measuring techniques. The results from this study will help

\footnotetext{
*Building 90-2000, LBNL, Berkeley, CA 94720 USAＡKMeier@LBL.gov
} 
formulate policies and programs to reduce standby power in California and the United States.

\section{METHODS}

Ten single and multi-family units were recruited from a range of income levels with occupancy varying from one to five persons. This group is too small to accurately represent the range of California homes, but it encompasses a great diversity of situations. In each home, we surveyed the appliances, measured each appliance's standby power consumption, and briefly measured the house's total electricity consumption, with all appliances switched off. In addition, we surveyed occupants about their future appliance purchases.

While several definitions for standby power have been proposed, there is no agreedupon procedure for measuring it. With few exceptions, we measured the minimum power while the appliance was plugged into the mains. This is consistent with the procedure used for measuring most Energy Star consumer home electronics. Appliance standby power was measured at the lowest level with a Power Line Watt Meter, model PLM-1-PK $( \pm 0.2 \mathrm{~W})$. Televisions, VCRs, stereos, and cable boxes were plugged into the watt-meter and switched off at the power button before being measured. This insured that the standby power was measured at the lowest point, as the standby draw of this mode is often lower than when the appliance is turned off with a remote control. Computers were measured in the mode that the owner specified as the most frequently used setting, generally the off mode for towers and the sleep mode for monitors. Cordless telephones were measured with the handsets removed from the chargers. Every appliance was photographed for further analysis.

The total standby power for each home was calculated by summing the individual appliance measurements. This measurement was verified by comparison with the electricity use indicated by the home's utility kilowatt-hour meter for approximately eight minutes while all appliances were either off or in standby mode. All appliances that could automatically cycle on, such as a refrigerator or water pump, were unplugged for the whole-house measurement. The utility meter measurement captured loads that could not be unplugged, such as security systems and outdoor motion sensors. In two cases it was impossible to unplug the refrigerator, in which case it was turned off.

If there was a large discrepancy between the two measurements, we searched for missing loads. These two methods allowed us to calculate both an upper and lower limit of total household standby power consumption. The sum of standby power from all household appliances comprised the lower limit while the home utility meter measurement comprised the upper limit. The annual electrical consumption was tallied from individual monthly utility bills, or obtained from the local utility. 
We were also curious about future changes in standby. We asked the occupants, "What do you foresee as the next three appliances you will purchase?" This information was used to estimate the percentage of new appliances which will have standby.

\section{RESULTS}

Ten homes were investigated and 190 appliances with standby were identified and measured. The results are summarized in Table 1. The majority of these appliances fit into one of three categories: entertainment, communications and computer hardware. Table 1 shows the household appliances, occurring in at least three houses or drawing more than $5 \mathrm{~W}$. These results can be compared to other compilations of measurements (Meier et al. 1999, Huber 1997). The ranges in observed standby are also similar to those reported by Meier et al.. In most cases, we found that the service provided by the appliance was identical, even though the maximum value was often four times greater than the minimum value.

Table 1: Measured appliance standby loads

\begin{tabular}{|c|c|c|c|c|}
\hline Appliance & $\begin{array}{c}\text { Average Load } \\
(W)\end{array}$ & $\begin{array}{c}\text { Minimum } \\
(W)\end{array}$ & $\begin{array}{c}\text { Maximum } \\
(W)\end{array}$ & $\begin{array}{l}\text { Number } \\
\text { Measured }\end{array}$ \\
\hline \multicolumn{5}{|l|}{ Entertainment } \\
\hline TV & 6.4 & 2.5 & 12 & 16 \\
\hline Set top box & 10.2 & 1.5 & 23 & 3 \\
\hline VCR & 5.3 & 1.3 & 11.3 & 13 \\
\hline Music box & 5.2 & 1.3 & 10 & 8 \\
\hline CD player & 2.2 & 0 & 6.8 & 6 \\
\hline Receiver & 2.8 & 0 & 8.8 & 7 \\
\hline Tape player & 1.0 & 0 & 2.3 & 5 \\
\hline \multicolumn{5}{|l|}{ Communications } \\
\hline Phone & 2.1 & 0.6 & 3.5 & 19 \\
\hline Answer machine & 2.2 & 1.8 & 2.9 & 3 \\
\hline Fax & 5.0 & 3.1 & 6.6 & 5 \\
\hline \multicolumn{5}{|l|}{ Computer } \\
\hline Tower & 1.2 & 0 & 2.3 & 8 \\
\hline Monitor & 2.0 & 0 & 5.9 & 8 \\
\hline Printer & 4.2 & 1.7 & 11.5 & 6 \\
\hline Subwoofer & 6.9 & 4 & 10.8 & 3 \\
\hline Laptop charger & 4.5 & 1.10 & 19.6 & 7 \\
\hline Copier & 5.1 & 0.3 & 9.8 & 2 \\
\hline \multicolumn{5}{|l|}{ Miscellaneous } \\
\hline Microwave & 2.8 & 1.6 & 3.9 & 7 \\
\hline Clock & 1.0 & 0.6 & 2.2 & 13 \\
\hline Furnace & 5.0 & 5.0 & 5.0 & 1 \\
\hline Telephone system & 24.5 & 24.5 & 24.5 & 1 \\
\hline
\end{tabular}


Our approach also permits a presentation of the data by home (Table 2). We found that the average standby load in the ten homes was $67 \mathrm{~W}$, but ranged from 14 to $169 \mathrm{~W}$. The households had an average of 19 appliances with standby power, ranging from 0.3 to $24 \mathrm{~W}$. Standby accounted for $5 \%$ to $26 \%$ of total annual electricity consumption. The appliances with the largest standby losses were televisions, set-top boxes and printers.

Each home's annual electricity consumption, based on utility bills, is also displayed. Average annual electricity use, $6769 \mathrm{kWh} / \mathrm{yr}$, was commensurate with the Northern California average of $6287 \mathrm{kWh} / \mathrm{yr}$ (PG\&E 1995). All ten homes used natural gas for space and water heating.

Table 2: Residential standby loads

\begin{tabular}{|c|c|c|c|c|c|}
\hline & $\begin{array}{c}\text { Annual } \\
\text { Electricity Use } \\
(k W \text {-hr/yr })\end{array}$ & $\begin{array}{c}\text { Standby } \\
\text { Power }(W)\end{array}$ & $\begin{array}{c}\text { Standby Power } \\
\text { as of Annual } \\
\text { Electricity Use }\end{array}$ & $\begin{array}{c}\text { Number of } \\
\text { Appliances } \\
\text { Measured }\end{array}$ & $\begin{array}{c}\text { Reduction in } \\
\text { Standby with 1 } \\
\text { Watt Target }\end{array}$ \\
\hline 1 & 4531 & 47 & $9 \%$ & 12 & $-75 \%$ \\
\hline 2 & 4977 & 39 & $7 \%$ & 15 & $-61 \%$ \\
\hline 3 & 1260 & 14 & $10 \%$ & 5 & $-64 \%$ \\
\hline 4 & 20060 & 144 & $6 \%$ & 46 & $-68 \%$ \\
\hline 5 & 6665 & 75 & $10 \%$ & 21 & $-72 \%$ \\
\hline 6 & 5470 & 48 & $8 \%$ & 15 & $-69 \%$ \\
\hline 7 & 5658 & 169 & $26 \%$ & 32 & $-81 \%$ \\
\hline 8 & 6126 & 61 & $9 \%$ & 16 & $-74 \%$ \\
\hline 9 & 5819 & 36 & $5 \%$ & 12 & $-67 \%$ \\
\hline 10 & 7122 & 41 & $5 \%$ & 19 & $-54 \%$ \\
\hline & & & & & $-68 \%$ \\
\hline
\end{tabular}

Nine homeowners responded to the survey of their next appliance purchases. Seven listed their next three purchases, while two listed only one appliance. Of the appliances listed, $70 \%$ will have standby power, while another $9 \%$ may have standby power (furnace and clothes dryer).

\section{DISCUSSION}

There was close agreement in the quantity of standby power measured by the two independent procedures used in this study (Figure 1). The only discrepancies were found in the homes in which it was impossible to unplug the refrigerators. Thus we regard the data presented as an accurate first estimation of standby power consumption in California homes. 
Figure 1: Correlation between two measurement techniques

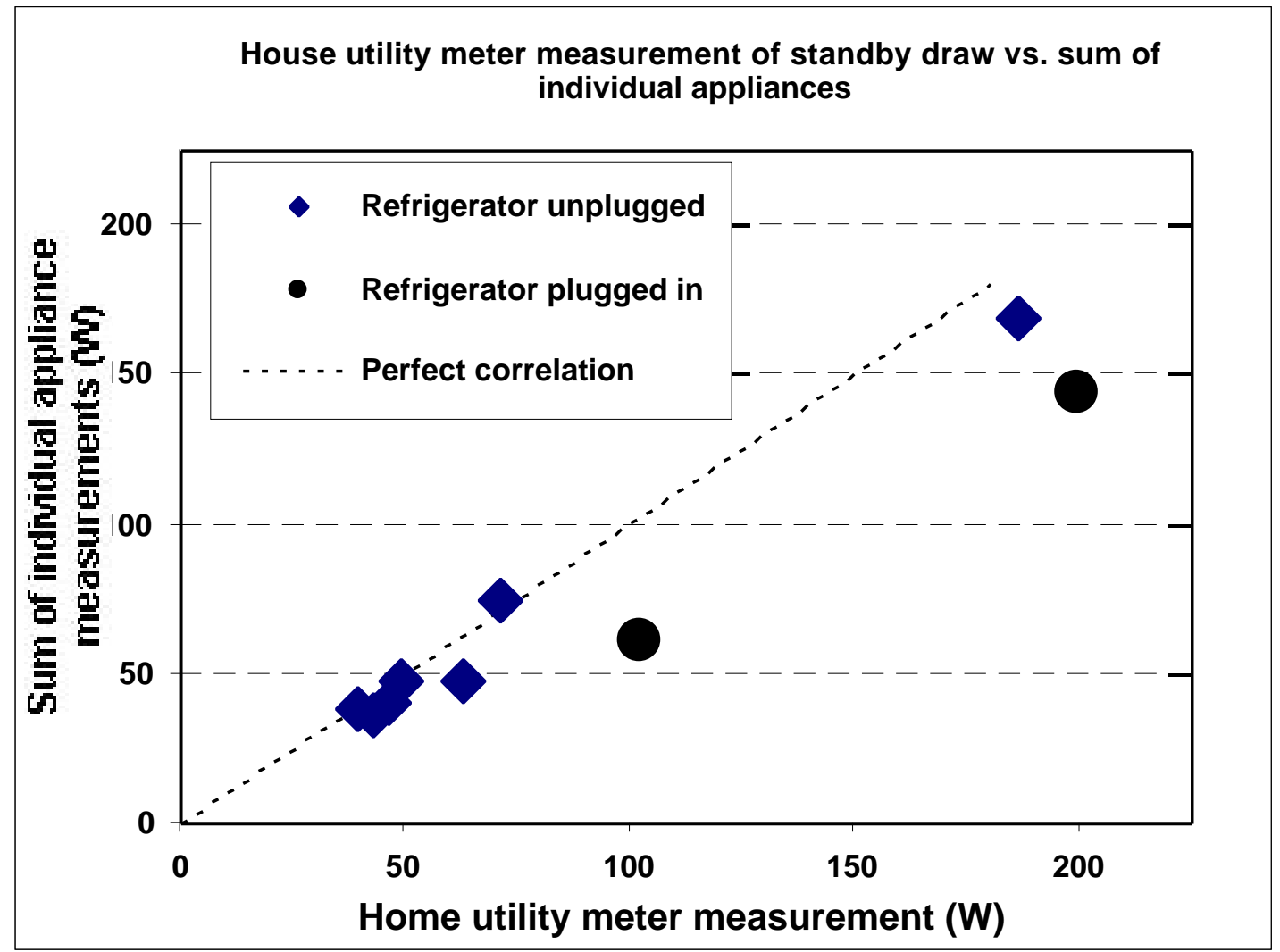

Does standby power consumption correlate with other features of the homes or characteristics of the occupants? We were unable to collect reliable data on some of the more likely factors, such as floor area and income; however, we were able to compare annual electricity use to measured standby. This relationship is shown in Figure 2. Standby power appears to increase with total electricity consumption, although there is wide variation at any given level of electricity consumption. The home at 20,000 $\mathrm{kWh} /$ year has a swimming pool and hot tub (whose pumps are major consumers of electricity). It also has more than twice the average number of appliances with standby, leading to a fraction consistent with the other homes. A simple regression indicates that each $1000 \mathrm{kWh} /$ year of non-heating electricity consumption correlates to about $8 \mathrm{~W}$ of standby. 
Figure 2: Annual electricity consumption versus standby power

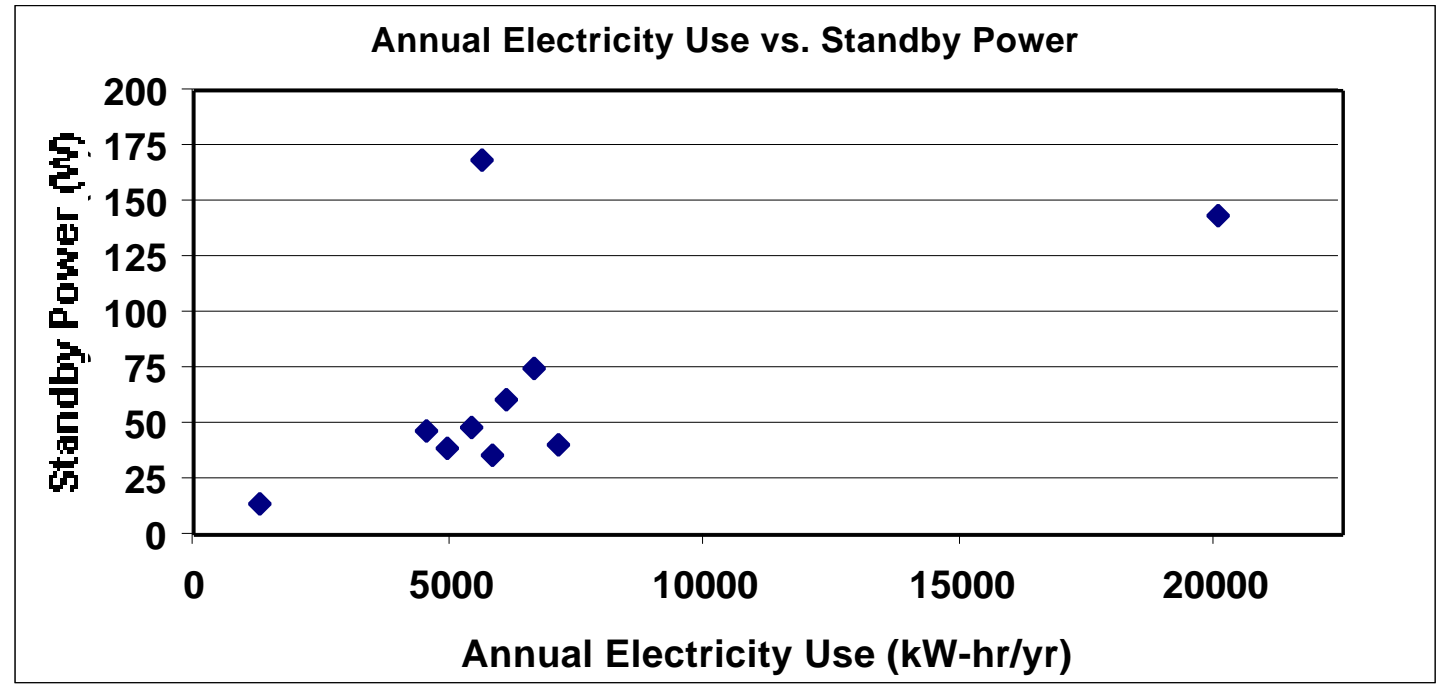

The $67 \mathrm{~W}$ of average standby observed in these homes is higher than the national average of the United States estimated at $50 \mathrm{~W}$ by Meier et al. 1999. The observed fraction of total electricity consumed by standby (9\%) is nearly twice the 5\% estimated by Meier for the United States. This inconsistency may arise because Northern California homes consume relatively little electricity for heating. Electricity consumption is higher in other areas of the United States where resistance heating is used for space and water heating, making standby power a lower fraction of total electricity use. Larger and more detailed studies are required to determine if the homes measured here are unusually high or if the earlier estimate was low.

It has been proposed that standby power be limited to $1 \mathrm{~W}$ (Meier et al. 1999). This study allows us to estimate the potential savings from this policy goal (Table 2). If all the existing appliances were replaced with units drawing only $1 \mathrm{~W}$, standby power consumption would be reduced by an average of $68 \%$. Note that, for many of the appliances, units drawing less than $1 \mathrm{~W}$ already exist and were observed in the ten homes. At least $70 \%$ of new appliance purchases in these homes will have standby. A policy encouraging manufacturers to reduce standby to $1 \mathrm{~W}$ or less in new appliances would significantly reduce the annual electricity consumption of homes used for standby power.

\section{CONCLUSIONS}

A study of ten homes cannot provide definitive evidence of the magnitude of standby power consumption. However, it can provide new insights to the scope of the problem and the opportunities for reducing it.

This study of ten homes suggests that earlier estimates of standby understate the actual value (or at least for California). The homes surveyed comprise a diverse sample 
representing the range of typical California residential electricity use. By employing two separate measurement strategies that bracket the true amount of standby, these results have an unusually high degree of confidence. Whole-house standby measurements based on short-term measurements of the house's utility meter proved to be reasonably accurate. Future studies of standby power may be able to rely on the utility meters instead of time-consuming measurements of individual appliances.

This study also demonstrates the potential savings by reducing standby. Similar appliances in these homes had wide ranges in standby power consumption, even though they all provide essentially the same service. Implementation of a $1-\mathrm{W}$ ceiling on standby could reduce standby energy consumption as much as $68 \%$.

\section{ACKNOWLEDGEMENT}

This work was supported by the Assistant Secretary for Energy Efficiency and Renewable Energy, Office of Building Technologies, of the U.S. Department of Energy under Contract No.DE-AC03-76SF00098.

We would also like to thank the Energy Foundation for its support of J.P. Ross.

\section{REFERENCES}

Huber, W. 1997. Standby Power Consumption in U.S. Residences. LBNL-41107. Lawrence Berkeley National Laboratories, Berkeley, Ca. USA

Meier, A., Rosen, K. 1999. Leaking Electricity in Domestic Appliances. Proceedings of 50th International Appliance Technical Conference, West Lafayette, Indiana, Steering Committee of the IATC.

Meier, A., Huber, W., Rosen, K. 1998. Reducing Electricity to 1 Watt. ACEEE Summer Study of Energy Efficiency in Buildings. August. Pacific Grove, California.

Meier, A., Huber, W. 1997. Results from the investigations on leaking electricity in the USA. First International Conference on Energy Efficiency in Household Appliances, Nov. 10-12, Florence, Italy.

Meier, A., Ranier, L., Greenberg, S. 1990. Miscellaneous Electrical Energy Use in Homes. Energy, V.17 No. 5: 509-518.

Molinder, O. 1997. Study on Miscellaneous Standby Consumption of Household Equipment. Prepared for the EU under contact 4.1031/E96-008. (EU-DG XVII, June 25) Brussels, Belgium.

Murakoshi, C. Personal communication. May 2000 
Nakagami, H., Tanaka, A., Murakoshi, C. 1997. Standby Electricity Consumption in Japanese Houses. Jyukanko Research Institute, Japan

Rath, U., Hellmann, R. 1997. Klimaschutz Durch Minderung von Leerlaufverlusten bei Elektrogeraten. Umweltbundesamt, Berlin, Forschungsbericht 20408541, UBA-FB 97-071.

Siderius, H. 1998. Standby Consumption in Households. Van Holsteijn en Kemma, Delft, The Netherlands.

Siderius, H. 1995. Household Consumption of Electricity in the Netherlands. Van Holsteijn en Kemma, Delft, The Netherlands.

Sidler, O. 2000. Campagne de mesures sur le fonctionnement en veille des appareils domestiques. Sophia-Antipolis (France), ADEME.

\section{Recommended Citation for this Report}

Ross, J. P. \& A. Meier. 2000. "Whole-House Measurements of Standby Power Consumption" In Proceedings of the Second International Conference on Energy Efficiency in Household Appliances. Naples (Italy): Association of Italian Energy Economics (Rome). Also published as Lawrence Berkeley National Laboratory Report LBNL-45967. 